

\title{
O genocídio em Ruanda e a inércia da comunidade internacional
}

\author{
Marina Gusmão de Mendonça ${ }^{1}$
}

Resumo: Entre abril e julho de 1994, o mundo assistiu impassível ao extermínio de mais de 800.000 pessoas em Ruanda. Tal morticínio é considerado o terceiro maior ocorrido desde 1950, comparável apenas àqueles verificados no Cambodja e em Bangladesh, na década de 1970. Entretanto, no caso de Ruanda, há um dado assustador: por ocasião da matança, a população do país era de aproximadamente 7.500.000 habitantes, sendo 6.300.000 hutus, 1.100 .000 tutsis e 100.000 pigmeus. Isto significa que cerca de $11 \%$ dos ruandeses e $3 / 4$ da população tutsi foram eliminados em apenas um trimestre. A comunidade internacional nada fez para evitar a matança. Pelo contrário: além de não intervir diretamente, a Organização das Nações Unidas (ONU) reduziu drasticamente o contingente da força de paz que mantinha em Ruanda, a despeito das advertências do General Roméo Alain Dallaire, comandante das tropas da UNAMIR, de que a tragédia estava a caminho. Passado o estupor provocado pelo genocídio, restou o problema fundamental da reconstrução do país. A esse respeito, é preciso assinalar as precaríssimas condições econômicas da região, o que é agravado pelo estraçalhamento do tecido social durante a matança. Ademais, não podemos esquecer que, se em 1994, o mundo assistiu passivamente à dilaceração de Ruanda, agora poucos estão preocupados com as dificuldades de reconstrução de um lugar que não tem importância estratégica e não dispõe de grandes riquezas naturais.Os fatores que levaram ao genocídio em Ruanda e a inércia da comunidade internacional para impedir o massacre são os temas deste artigo.

Palavras-chave: África, Ruanda, Genocídio, Organização das Nações Unidas, UNAMIR

\footnotetext{
${ }^{1}$ Bacharel em História e em Direito pela Universidade de São Paulo (USP); Mestre e Doutora em História Econômica pela Faculdade de Filosofia, Letras e Ciências Humanas da Universidade de São Paulo (FFLCHUSP); possui Pós-Doutorado em Ciências Sociais pela Faculdade de Filosofia e Ciências da Universidade Estadual Paulista (UNESP) - Campus de Marília; Professora Adjunta temporária da Escola Paulista de Política, Economia e Negócios (EPPEN) da Universidade Federal de São Paulo (UNIFESP); Professora Colaboradora do Programa de Pós-Graduação em Ciências Sociais da Faculdade de Filosofia e Ciências da Universidade Estadual Paulista (UNESP) - Campus de Marília; autora de Progresso e Autoritarismo no Brasil (Pensieri, 1992); O Demolidor de Presidentes (Códex, 2002); Histórias da África (LCTE, 2008); Formação Econômica do Brasil (Thomson, 2002) e Formação Econômica da América Latina (LCTE, 2012), os dois últimos em colaboração com o Prof. Dr. Marcos Cordeiro Pires (endereço eletrônico: marinamendonca@ uol.com.br).
} 


\section{Rwanda genocide and the inaction of the international community}

Abstract: Between April and July 1994 the world seemed not affected by the extermination of more than 800.000 people in Rwanda. This is the third largest massacre since 1950 and can only be compared to those occurred in Cambodia and Bangladesh in the1970's. But in the case of Rwanda there is something truly alarming: at the time of the genocide there were about 7.500.000 inhabitants in the country; 6.300.000 Hutus; 1.100.000 Tutsis; and 100.000 pigmies, what means that about $11 \%$ of Rwandans and $3 / 4$ of the Tutsi population were killed in a period of three months.

The international community did nothing to avoid the massacre, and the United Nations (UN) even reduced its peacekeepers in Rwanda despite Roméo Alain Dallaire, the general commander of the UNAMIR troops in the country, having warned about the tragedy to come. In the aftermath of the world's astonishment with the genocide the fundamental task is the problem of country's reconstruction under very difficult economic conditions remained, now exacerbated by the social laceration it provoked. In addition, it cannot be forgotten that if in 1994 the world did nothing to avoid the massacre, nowadays there are still very few people worried about the reconstruction of a place poor in natural resources.

The article analyses the conditions that conducted to Rwanda's genocide and the inaction of the international community to avoid it.

Key Words: Africa, Rwanda Genocide, UN, UNAMIR 
Entre abril e julho de 1994, o mundo assistiu impassível ao extermínio de mais de 800.000 pessoas em Ruanda. Tal morticínio pode ser considerado o terceiro maior ocorrido desde 1950, comparável apenas àqueles verificados no Cambodja e em Bangladesh, na década de 1970. Entretanto, no caso de Ruanda, há um dado assustador: por ocasião da matança, a população do país era de aproximadamente 7.500.000 habitantes, sendo 6.300.000 hutus, 1.100.000 tutsis e 100.000 pigmeus, cujos descendentes são chamados de $t w a s^{2}$. Isto significa que cerca de $11 \%$ dos ruandeses e $3 / 4$ da população tutsi foram eliminados em apenas um trimestre.

É preciso considerar também que as divisões étnicas em Ruanda são extremamente fluidas. Na verdade, a maioria da população fala a mesma língua, freqüenta os mesmos lugares e casa-se entre si. Cerca de $1 / 4$ dos ruandeses têm bisavós hutus e tutsis ${ }^{3}$. Contudo, grande número daqueles considerados hutus decidiram exterminar pessoalmente os tutsis e os hutus moderados em abril de 1994, com requintes de crueldade inimagináveis.

Diante de tal barbárie, algumas perguntas são fundamentais: por que ocorreu o genocídio? O que levou a maioria hutu da população de Ruanda a decidir exterminar seus conterrâneos - e até mesmo amigos e familiares - tutsis? Por que a comunidade internacional não interveio? Como é possível reconstruir um país cujo tecido social foi de tal forma dilacerado?

Neste texto, procuraremos recapitular brevemente a História de Ruanda e tentar encontrar algumas possíveis respostas a estas perguntas.

\section{Características geográficas, sociais, econômicas, demográficas e culturais de Ruanda}

Ruanda é um país montanhoso, de pouco mais de $26.000 \mathrm{~km}^{2}$, encravado na região dos Grandes Lagos da África Centro-Oriental. Geograficamente dividido em colinas, faz fronteira com Uganda, Burundi, República Democrática do Congo e Tanzânia. Em decorrência da altitude (em algumas regiões chega a 3.000 m), o clima é temperado, com regime de chuvas moderado, o que, em grande medida, livra o país da infestação por malária e pela mosca tsétsé, que constituem grandes problemas para a maioria das nações africanas localizadas na zona equatorial. A principal atividade econômica é a agricultura.

\footnotetext{
${ }^{2}$ Veja-se: DIAMOND, Jared. Malthus na África: o genocídio em Ruanda In: Colapso. Rio de Janeiro: Record, 2005 , p. 385.

${ }^{3}$ Idem, ibidem.
} 
Em função dessas características, no século XIX a densidade populacional de Ruanda já era alta $^{4}$, tendo crescido, desde então, a uma taxa de aproximadamente 3\%/ano. Em consequiência disso, Ruanda e o Burundi (cujas características geográficas, étnicas, demográficas e culturais são semelhantes) se tornariam os países mais densamente povoados da África. No caso específico de Ruanda, a nação tinha, em 1993, uma das maiores densidades populacionais do mundo, com cerca de 293 habitantes $/ \mathrm{km}^{2^{5}}$. Todavia, a agricultura não é mecanizada, o que leva à baixa produtividade e à quase ausência de excedentes comercializáveis.

Quanto à composição da população, esta é formada pelos chamados banyarwandas, sendo aproximadamente $85 \%$ hutus e $14 \%$ tutsis, além de $1 \%$ de pigmeus ${ }^{6}$. No entanto, como já dito anteriormente, esta divisão é extremamente fluida, e não corresponde a diferenças étnicas específicas. Na verdade, elas foram estabelecidas ao longo dos séculos - e intensificadas pelos colonizadores europeus - em função de posições ocupadas na escala social.

De fato, ao que tudo indica, o povoamento inicial de Ruanda foi feito por pigmeus. No que diz respeito aos hutus e tutsis, sua origem não é bem conhecida. Conta-se, no entanto, que os hutus seriam bantos provenientes do sul e do oeste, tendo se estabelecido em Ruanda antes dos tutsis, povo nilótico oriundo do norte e do leste, e que teriam se imposto como senhores dos hutus. Do ponto de vista das características físicas, os hutus teriam pele escura, rostos redondos, nariz achatado, lábios grossos e mandíbulas quadradas, enquanto os tutsis seriam mais altos, com pele menos escura, rosto delgado, nariz e queixo estreitos e lábios finos. Todavia, a miscigenação sempre foi muito grande, criando-se também uma cultura comum, com língua, religião e valores políticos e sociais compartilhados ${ }^{7}$. Os chefes, chamados mwamis, eram considerados divindades absolutas, a própria encarnação de Ruanda. Ao longo da História, tanto hutus como tutsis ocuparam o cargo. Enfim, os etnógrafos entendem que

\footnotetext{
${ }^{4}$ Veja-se: KI-ZERBO, Joseph. História da África negra. Lisboa: Publicações Europa-América, s.d., v. 2, p. 241.

${ }^{5}$ Veja-se: DIAMOND, Jared, 2005, op. cit., p. 386.

${ }^{6}$ Veja-se: MAQUET J. J. El reino de Ruanda In: FORDE, Daryll, org. Mundos africanos. México: Fondo de Cultura Económica, 1975, pp. 249-251.

${ }^{7}$ Sobre a evolução histórica de Ruanda, vejam-se especialmente: VANSINA, Jan. Antecedents to modern Rwanda. Madison, Wisconsin: The University of Wisconsin Press, 2004; e KI-ZERBO, Joseph, s.d., op. cit, 2 v.
} 
hutus e tutsis não podem ser considerados grupos étnicos diferenciados ${ }^{8}$. Quanto ao Estado ruandês, surgiu no século XVII, quando Ruganzu Ndori, oriundo da área que, atualmente, corresponde à Tanzânia, penetrou na região e fundou o Reino de Ruanda, absorvendo as pequenas organizações políticas então existentes ${ }^{9}$.

A sociedade ruandesa se dividia em castas e, tradicionalmente, os hutus eram agricultores e os tutsis criadores de gado ${ }^{10}$. Aliás, a palavra tutsi se tornou sinônimo de elite econômica e política. A riqueza dos tutsis era fundada na posse de rebanhos zebus, e as vacas eram consideradas sagradas e intocáveis, não podendo ser abatidas. Os tutsis se alimentavam do leite e do sangue das vacas, e todo o trabalho era feito por homens. A vaca representava, portanto, riqueza e poder ${ }^{11}$, e o maior rebanho pertencia ao mwami. Os agricultores hutus, por sua vez, eram submetidos aos tutsis, entregando-lhes como tributo parte da colheita, em troca de proteção e do direito de uso de uma vaca ${ }^{12}$. Quanto aos twas, estes nunca passaram de $1 \%$ da população, e sempre constituíram um grupo marginalizado, sem quaisquer direitos ${ }^{13}$.

A acentuação desta divisão teria ocorrido depois de 1860, quando o mwami Rwabugiri (tutsi) subiu ao trono e deu início a campanhas políticas e militares com o objetivo de expandir e consolidar seu domínio por todo o território. E, tendo em vista o caráter sagrado do mwami, Rwabugiri conseguiu moldar a sociedade à sua própria imagem, isto é, os tutsis foram favorecidos com altos cargos civis e militares e passaram a gozar de maior poder econômico, subordinando os hutus como seus vassalos. Porém, a identificação social

\footnotetext{
${ }^{8}$ Veja-se: GOUREVITCH, Philip. Gostaríamos de informá-lo de que amanhã seremos mortos com nossas famílias. São Paulo: Companhia das Letras, 2006, p. 45.

${ }^{9}$ A respeito da formação do Estado de Ruanda, veja-se: TAYLOR, Christopher C. Sacrifício rei, Estado ruandês $e$ genocídio. Caderno CRH. Salvador, v. 24, $\mathrm{n}^{\circ}$ 61, janeiro-abril/2011 (disponível em: http://www.scielo.br/scielo.php?script=sci arttext\&pid=S0103-49792011000100005\&Ing=pt\&nrm=iso - acesso em 27/7/2013).
}

${ }^{10}$ A esse respeito, veja-se o comentário de B. A. Ogot: "a origem dos pastores nessa região é incerta. Alguns autores afirmaram que eles vieram do norte mas, como observou J. K. Rennie, 'é impossível excluir uma origem local do pastorialismo (...)'. Em segundo lugar, é necessário revisar a opinião - tão amplamente difundida - de que os pastores teriam chegado à região como conquistadores, estabelecendo aristocracias pastoris sobre as populações de agricultores. (...) podem-se citar vários casos de coexistência pacífica entre pastores e agricultores" (OGOT, B. A. A região dos grandes lagos In: NIANE, D. T., org. História geral da África: a África do século XII ao século XVI. São Paulo: Ática/UNESCO, 1988, v. 4, p. 524.

${ }^{11}$ Sobre o fundamento do poder dos tutsis, veja-se: MAQUET, J. J., 1975, op. cit., pp. 265-273.

${ }^{12}$ Veja-se: KAPUSCINSKI, Ryszard. Uma palestra sobre Ruanda In: Ébano. São Paulo: Companhia das Letras, 2002, p. 187.

${ }^{13}$ Veja-se: GOUREVITCH, Philip, 2006, op. cit., p. 45. 
continuou a ser determinada por fatores tais como origem do clã, religião, clientela etc., permitindo certa permeabilidade entre tutsis e hutus ${ }^{14}$.

\section{O período colonial e a acentuação da divisão social segundo critérios étnicos}

Quando da partilha da África, no final do século XIX, a chamada "ciência das raças" encontrava-se em voga na Europa e, no caso dos estudos sobre os povos da África Central, prevalecia a hipótese hamítica, proposta pelo explorador inglês, John Hanning Speke, em $1863^{15}$. Segundo esta teoria, a civilização teria sido introduzida na região por um povo caucasóide mais alto, de origem etíope, descendente do Rei Davi e, portanto, superior aos negros nativos. Para Speke, essa "raça" seria de cristãos perdidos, o que permitia supor que deveriam receber educação britânica e tornarem-se superiores em tudo, exatamente como os ingleses ${ }^{16}$.

Por ocasião da Conferência de Berlim (1884-1885), os territórios que hoje correspondem a Ruanda e Burundi foram atribuídos à Alemanha. Assim, em 1894, o Conde von Götzen se tornaria o primeiro homem branco a visitar Ruanda e sua corte, onde, em 1897, instalou os primeiros postos administrativos e impôs o governo indireto. Porém, em 1895, havia falecido o mwami Rwabugiri, desencadeando-se violenta luta pela sucessão entre os tutsis. Em consequiência, os líderes dos clãs mais fracos passaram a colaborar com os chefes alemães, que concederam a membros da elite tutsi proteção e liberdade, o que lhes permitiu consolidar a posse sobre terras e submeter os hutus.

Depois da Primeira Guerra Mundial, a Liga das Nações transferiu a administração de Ruanda e do Burundi para a Bélgica, que passou a basear sua política colonial na suposta divisão étnica entre hutus e tutsis, usando o pretexto do mito hamítico para dividir os ruandeses. O governo belga chegou mesmo a enviar cientistas para tirarem as medidas da população, os quais concluíram que os tutsis teriam uma compleição física naturalmente aristocrática. Daí à reorganização da sociedade em função de supostas linhas étnicas foi um

\footnotetext{
${ }^{14}$ Veja-se: COQUERY-VIDROVITCH, C.; MONIOT, H. África negra: de 1800 a nuestros días. Barcelona: Labor, 1976, pp. 38-39.

15 Sobre a hipótese hamítica, elaborada por Speke, veja-se: SPEKE, John Hanning. The journal of the discovery of the source of the Nile. Nova York: Harper \& Brothers, 1864 (disponível em: http://books.google.com.br/books?id=W1YMAAA).
}

${ }^{16}$ Veja-se: GOUREVITCH, Philip, 2006, op. cit., pp. 48-52.

BJIR, Marília, v.2, n.2, p.300-328 Maio/Ago. 2013 
passo, para o quê os belgas contaram com o apoio da Igreja Católica. Em seguida, as estruturas sociais que garantiam alguma autonomia local aos hutus foram desmanchadas, e os tutsis acentuaram a exploração por meio do trabalho compulsório e da cobrança de tributos.

Em 1931, o governo belga e a Igreja Católica promoveram a deposição do mwami, e empossaram em seu lugar Rudahigwa, que se converteu ao catolicismo e renunciou à sua condição de divindade. Em seguida, houve uma verdadeira corrida para a conversão, e Ruanda logo se tornou o país mais católico da África. Pouco depois, entre 1933/1934, os belgas realizaram um censo com a finalidade de emitir documentos de identidade étnica, o que acabou por permitir que a metrópole aperfeiçoasse a administração com base na segregação. O sistema educacional foi organizado de forma a promover a discriminação aberta em favor dos tutsis, que passaram a deter os cargos políticos e administrativos. Este sistema liquidaria a identidade nacional, desenvolvendo-se, a partir de então, um discurso excludente baseado na diferenciação de raças e na superioridade de uma delas (no caso, os tutsis).

Depois da Segunda Guerra Mundial, a administração belga ficou subordinada à supervisão da Organização das Nações Unidas (ONU). Porém, naquele momento, o movimento independentista ganhava força em todo o continente africano, e a população hutu passou a reivindicar um governo da maioria e a lutar por uma revolução social. Assim, em março de 1957 - portanto, num período em que o colonialismo estava sendo posto em xeque em todo o continente -, alguns intelectuais ruandeses divulgaram o "Manifesto Hutu", no qual, embora clamassem por um governo democrático, corroboravam o mito hamítico, mas invertido. Ou seja: os tutsis seriam invasores, e Ruanda era, por direito, uma nação de maioria hutu, motivo pelo qual rejeitavam a abolição da carteira de identidade étnica. Logo em seguida, surgiram partidos que conclamavam as massas a se agregar em torno da identidade hutu.

Dois anos depois, em $1^{\circ}$ de novembro de 1959, Dominique Mbonyumutwa, ativista hutu e sub-chefe administrativo da província de Gitarama, foi espancado por militantes tutsis. E, apesar de falso, o boato de que Mbonyumutwa havia morrido logo se espalhou. Em menos de 24 horas, bandos de hutus atacaram autoridades tutsis e abateram grande parte do rebanho, iniciando-se uma revolta que se alastrou por todo o país. Um dos maiores entusiastas da rebelião era o coronel belga, Guy Logiest.

Para agravar a situação, em fevereiro de 1960, o mwami, enfermo, foi ao Burundi para se tratar com um médico belga, mas acabou morrendo. Os tutsis logo espalharam o boato de 
que ele havia sido envenenado. Diante do acirramento do conflito, o Cel. Logiest promoveu um golpe de Estado, substituindo os chefes tutsis por hutus. As eleições, realizadas em meados daquele ano, levaram os hutus a conquistarem $90 \%$ dos cargos mais importantes. Posteriormente, em outubro de 1960, depois da instalação de um governo provisório, liderado por Grégoire Kayibanda, um dos autores do "Manifesto Hutu”, o Cel. Logiest anunciou que a revolução estava encerrada. Finalmente, em janeiro de 1961, Ruanda foi declarada uma república. E, em 1962, conquistou a autonomia plena, sendo Kayibanda empossado presidente $^{17}$.

\section{A independência de Ruanda e o agravamento dos conflitos sociais}

A independência, a proclamação da república e a ascensão de Kayibanda ao poder não propiciaram, contudo, a paz. Pelo contrário: a falta de carisma e de apoio ao presidente levaram-no a conclamar a população a manter vivo o espírito da revolução. O pretexto eram as incursões periódicas de tutsis exilados ao território ruandês, e o objetivo era claro: os hutus deveriam matar os inyenza (que significa baratas, como eram chamados os tutsis), permitindo a manutenção da hegemonia hutu. Assim, em dezembro de 1963, por ocasião de mais uma invasão de tutsis a partir do Burundi, o governo declarou estado de emergência e passou a organizar unidades hutus de auto-defesa. Em conseqüência, ocorreu um verdadeiro massacre de tutsis entre dezembro/1963 e janeiro/1964. Diante da perseguição, calcula-se que, em meados de 1964, cerca de 250 mil tutsis haviam fugido do país. É preciso assinalar que, já nesta ocasião, lideranças religiosas católicas e de organizações humanitárias foram acusadas de cumplicidade com o morticínio.

Embora o governo hutu tenha logrado matar e expulsar grande parcela da população tutsi de Ruanda, e apesar da difusão do mito hamítico invertido, a situação não se acalmou. Isto se explica pelo fato de que, no vizinho Burundi, os tutsis haviam conseguido manter a hegemonia. Assim, em 1972, os hutus do Burundi iniciaram uma rebelião, que foi sufocada. A seguir, o exército desencadeou uma campanha de extermínio dos hutus mais instruídos. O resultado foi a morte de mais de 100 mil hutus, além de 200 mil refugiados em Ruanda, agravando o problema alimentar e a luta pela posse de terra.

Em resposta, Kayibanda encarregou o chefe do exército, General Juvénal Habyarimana, de organizar os chamados Comitês de Defesa Pública. Diante disso, mais de

${ }^{17}$ Idem, pp. 48-62

BJIR, Marília, v.2, n.2, p.300-328 Maio/Ago. 2013 
100 mil tutsis fugiram do país, exilando-se principalmente em Uganda. Aliás, calcula-se que, desde 1959, cerca de 1 milhão de tutsis ruandeses estavam refugiados naquele país. O êxito de Habyarimana na campanha contra os tutsis promoveu seu fortalecimento e, em julho de 1973, ele deu um golpe de Estado, proclamando-se presidente. Logo a seguir, pediu aos hutus uma trégua nos ataques contra os tutsis, embora organizasse o Movimento Revolucionário Nacional pelo Desenvolvimento (MRND), mantendo as regras de cotas para os tutsis. Segundo Teresa Nogueira Pinto,

"o MRND apresentava traços de partido totalitário: a militância era imposta à grande
maioria da população e todos os chefes e quadros administrativos tinham de ser
membros do partido, que tinha células em todas as colinas. Em cada célula eram
distribuídos trabalhos comunitários (...) e realizavam-se cerimônias de demonstração
de lealdade ao partido (...). O MRND controlava ainda os média (sic) e todas as
associações civis"18.

Saliente-se que, a partir de 1975, os governos da Bélgica e da França passaram a fornecer grande ajuda financeira e militar ao governo de Habyarimana. Contudo, a situação em Uganda mudou no início da década de 1980, com o acirramento da luta contra a ditadura de Milton Obote, sob a liderança de Yoweri Museveni. O exército rebelde - do qual participavam milhares de ruandeses exilados - sairia vitorioso em 1986. Museveni foi proclamado presidente, provocando temores em Habyarimana e seu grupo. É preciso assinalar também que, apesar da trégua com os tutsis, Habyarimana sempre havia se recusado a permitir a volta dos exilados, sob o pretexto de que Ruanda estava lotada. Em face da situação em Uganda, tornou ilegal qualquer contato da população ruandesa com os refugiados. A esse respeito, porém, é preciso fazer algumas considerações.

Nessa ocasião, cerca de $95 \%$ do território ruandês eram ocupados pela agricultura, e a família média no país compunha-se de oito pessoas, que viviam da produção agrícola em áreas não superiores a $2.000 \mathrm{~m}^{2}$. De outra parte, e em virtude da crise econômica mundial, os preço dos principais produtos de exportação de Ruanda - café e chá - despencaram no mercado internacional, reduzindo-se também a ajuda estrangeira. Diante disso, as lideranças do governo de Habyarimana - cuja corrupção era imensa -, e que já haviam iniciado a apropriação do Estado ruandês, acentuaram sua ação, por meio do controle de negócios paraestatais, do aparato político do MRND e do Exército, sob a chefia de Agathe Kanzinga, mulher de Habyarimana e filha de uma família da elite de Ruanda. O grupo de Agathe

\footnotetext{
${ }^{18}$ PINTO, Teresa Nogueira. Ruanda: entre a segurança e a liberdade. Relações Internacionais. Lisboa, $\mathrm{n}^{\mathbf{o}} 32$, $\begin{array}{lllll}\text { dezembro/2011, } & \text { p. } & 46 & \text { (disponível }\end{array}$ http://www.scielo.gpeari.mctes.pt/scielo.php?script=sci arttext\&pid=S164591992011000400004\&Ing=pt\&nrm=iso - acesso em 27/7/2013).
} 
Kanzinga, conhecido como "le clan de Madame", passou a ser chamado de Akazu, núcleo daquilo que viria a se constituir, posteriormente, no "Poder Hutu".

No entanto, o governo de Habyarimana começou a sofrer com as investidas da oposição interna, tanto que, em 1987, passaria a circular o jornal Kanguka, editado por um hutu e sustentado por um tutsi. O periódico fazia duras críticas ao establishment, propondo uma análise da situação de Ruanda segundo um viés econômico e não étnico.

Diante da crise econômica, o governo ruandês pediu auxílio ao Fundo Monetário Internacional (FMI) e ao Banco Mundial (BIRD), que imediatamente exigiram a implantação de duras medidas de ajuste, tais como cortes no orçamento de 1989, aumento de impostos e ampliação do trabalho compulsório. Por outro lado, na mesma época, chuvas torrenciais agravaram as condições, criando-se bolsões de fome no país. A situação tornou-se tão difícil que aproximadamente $60 \%$ do orçamento de Ruanda provinham de ajuda externa.

Nesse mesmo ano, o fim da guerra fria significaria mais um golpe para o governo de Habyarimana e seu grupo, pois imediatamente as potências ocidentais - principalmente a França - passaram a condicionar a continuidade da ajuda externa à democratização do país. Assim, em junho de 1990, o governo ruandês viu-se obrigado a ceder, anunciando o estabelecimento de um sistema multipartidário, embora a Akazu procurasse ampliar o controle sobre a máquina estatal. Dessa forma, no início de 1990, Agathe Kanzinga convenceria os líderes da Akazu a lançar o jornal Kangura, em defesa do governo. O editor contratado foi Hassan Ngeze.

Poucos meses depois $-1^{\circ}$ de outubro de 1990 -, a Frente Patriótica de Ruanda (FPR), exército guerrilheiro composto de exilados em Uganda, invadiu o país, declarando guerra ao regime de Habyarimana. O governo reagiu quatro dias depois, anunciando que havia esmagado um ataque rebelde à capital, Kigali, o que não era verdade. Mas o fato é que a ofensiva da FPR ofereceu à oligarquia que controlava Ruanda o pretexto que faltava para desencadear o assalto final ao Estado: os tutsis do país passaram a ser considerados cúmplices da FPR e os hutus que não apoiassem o governo foram tidos como traidores. Assim, nos últimos meses de 1990, cerca de 10 mil pessoas foram presas em Ruanda, enquanto os hutus da aldeia de Kibilira foram comunicados de que o trabalho comunal daquele mês seria combater os vizinhos tutsis. O resultado foi o assassinato de aproximadamente 350 tutsis e a fuga de cerca de 3 mil pessoas em apenas três dias. Este evento é considerado pelos estudiosos o marco inicial do genocídio. 


\section{A preparação do genocídio}

Do ponto de vista ideológico, a oligarquia da Akazu procurava reviver o mito hamítico e a retórica da revolução, difundindo a idéia de que as relações entre hutus e tutsis constituem uma sucessão de pogroms, e que Ruanda é pequena demais para abrigar povos tão diferentes. Assim, o erro cometido em 1959 teria sido permitir que os tutsis fugissem do país, em vez de exterminá-los. Era chegada a hora de corrigir o equívoco.

Em dezembro de 1990, Ngeze publicou no Kangura os 10 mandamentos hutus, que passaram a ser divulgados insistentemente por todo o país. Por outro lado, nesse mesmo mês, o jornal saudava François Mitterrand, então presidente da França, por ter enviado um contingente de pára-quedistas, que ajudou o governo de Ruanda a conter o avanço da FPR.

A esse respeito, é preciso que se esclareçam dois pontos: primeiramente, houve, na França, intensa pressão do lobby pró-africano para que François Mitterrand interviesse. Como salientou Ryszard Kapuscinski, esse grupo é composto, em grande parte, de homens que participaram da administração colonial e que, depois da independência, voltaram à Europa, onde permaneceram deslocados. Para eles, a França seria uma comunidade de povos de língua francesa, e um ataque a um país francófono significava um ataque à própria França ${ }^{19}$. Em segundo lugar, Jean-Christophe Mitterrand, filho do presidente, era, na ocasião, comissário de assuntos africanos do Ministério do Exterior e grande comerciante de armas. Assim, o envolvimento francês na guerra foi-se acentuando cada vez mais: de um lado, motivado pelo fato de a França procurar defender um território francófono, tendo em vista que a maior parte dos rebeldes era originária de Uganda, uma área anglófona; de outro, pelo interesse em vender armas e em controlar a economia do país.

Apesar do auxílio francês para conter os rebeldes, a FPR faria nova investida em janeiro de 1991, quando tomou Ruhengeri, cidade natal de Habyarimana. Todavia, as tropas francesas conseguiram expulsá-los. Com essa vitória, o governo ruandês - com o apoio da França, do Egito e da África do Sul, que continuavam a enviar armas - passou a adotar nova estratégia: a formação de milícias compostas de jovens sem quaisquer perspectivas em face da crise econômica. A vanguarda do movimento era representada pela Interahamwe ("Aqueles que lutam juntos"), com origem nas torcidas organizadas de futebol e na Akazu. Assim, em março de 1992, a Rádio Ruanda divulgaria a descoberta de um suposto plano tutsi para matar hutus. Em represália, membros da milícia de Bugesera mataram 300 tutsis em apenas três

\footnotetext{
${ }^{19}$ Veja-se: KAPUSCINSKI, Ryszard, 2002, op. cit., p. 198.
} 
dias, enquanto autoridades locais se aproveitaram dos fatos para se apoderarem das terras dos mortos. Diante dos protestos internacionais, o governo alegou que se tratava de manifestações espontâneas, embora os massacres fossem precedidos de comícios.

A mobilização popular continuava, e o povo de Ruanda passou a ser considerado como arma pelos líderes, isto é, todos os hutus teriam de matar todos os tutsis. Era claramente uma estratégia de controle completo do Estado por parte de uma oligarquia, que mobilizava a população em seu favor com base numa pretensa identidade étnica, consubstanciada naquilo que ficou conhecido como "Poder Hutu",20.

Essa estratégia seria gravemente ameaçada em agosto de 1993, quando a comunidade internacional promoveu a assinatura dos Acordos de Arusha (cidade localizada na Tanzânia), entre o governo ruandês e a FPR. Pelos tratados, haveria a garantia de retorno dos exilados e a fusão entre os exércitos nacional e rebelde, formando-se, assim, uma única força de defesa, além do estabelecimento de um governo de transição, composto de representantes de todos os partidos. Habyarimana permaneceria no cargo até a realização de eleições, com poder apenas formal, e o cumprimento dos acordos seria supervisionado por uma força de paz da ONU (UNAMIR), que chegaria ao país no final de $1993^{21}$.

É preciso assinalar ainda que, na mesma ocasião da assinatura dos Acordos de Arusha, um hutu foi empossado no governo do Burundi, depois de 30 anos de ditadura tutsi. Porém, em fins de outubro de 1993, o novo presidente seria assassinado por militares tutsis, provocando um levante dos hutus e violenta repressão por parte do exército tutsi. Nos conflitos, cerca de 50 mil pessoas foram mortas ${ }^{22}$.

Por outro lado, inconformadas com os Acordos de Arusha, lideranças do Poder Hutu passaram a acusar Habyarimana de traição, por meio da Rádio Mille Collines (RTLM),

\footnotetext{
${ }^{20}$ A cronologia dos fatos a seguir pode ser vista em: UNITED NATIONS. Report of the independent inquiry into the actions of the United Nations during the 1994 genocide in Rwanda (disponível em: www.un.or/news/dh/latest/rwanda.htm - daccess-dds-nyun.org/doc/UNDOC/GEN/N99/395/50/IMG/N9939550.pdf?OpenElement - acesso em 27/7/2013).
}

${ }^{21}$ A gravidade da situação era conhecida da ONU desde abril de 1993, tendo em vista o informe sobre a visita do
Relator Especial da Comissão de Direitos Humanos, Waly Bacrew Ndiaye, que descreveu a ocorrência de
execuções extra-judiciais, sumárias e arbitrárias. E o fato de esta violência estar sendo praticada contra a
população tutsi levou Ndiaye a usar a palavra genocídio. De fato, citando a Convenção do Genocídio, afirmou
que os casos de violência indicavam "muito claramente que as vítimas, na maioria tutsis, estavam sendo alvo de
ataques unicamente por sua origem étnica, sem nenhuma outra razão objetiva" (veja-se: UNITED NATIONS.
Report of the independent inquiry into the actions of the United Nations during the 1994 genocide in Rwanda,
op. cit., pp. 5-6 - tradução nossa: MGM).

${ }^{22}$ Vejam-se: GOUREVITCH, Philip, 2006, op. cit.; e UNITED NATIONS. Report of the independent inquiry into the actions of the United Nations during the 1994 genocide in Rwanda, op. cit. 
fundada por membros da Akazu, e que transmitia discursos inflamados e canções de astros simpatizantes do governo. Habyarimana tentaria, então, resistir à implantação efetiva dos acordos, promovendo ataques cada vez mais freqüentes à oposição. Ao mesmo tempo, Kigali que, pelos acordos, havia sido designada zona livre de armas, transformou-se num verdadeiro bazar de armamentos, abastecido por aviões franceses carregados de facões importados da China e distribuídos gratuitamente à população.

Diante do agravamento da situação, em 11 de janeiro de 1994, Roméo Alain Dallaire, general canadense comandante da UNAMIR, enviou um telegrama ao Assessor Militar da Secretaria Geral da ONU, General Maurice Baril, advertindo sobre a movimentação da Interahamwe e do perigo de uma guerra $\operatorname{civil}^{23}$. Em resposta, a ONU avisou que não interviria, sugerindo a Dallaire que partilhasse as informações com Habyarimana e com as embaixadas da Bélgica, da França e dos Estados Unidos (EUA), o que foi feito ${ }^{24}$. Mas nenhuma providência foi tomada, apesar de continuar a mobilização da população para o genocídio.

Tanto isso é verdade que, em março de 1994, o jornal Kangura divulgou em letras garrafais: "Habyarimana vai morrer em março" 25 . E, embora aquele mês tenha terminado sem que o fato se comprovasse, no dia 6 de abril de 1994, o avião em que estavam Habyarimana e Cyprien Ntaryamira, presidente hutu do Burundi, foi derrubado perto do aeroporto de Kigali, quando voltava de Dar es Salaam, maior cidade da Tanzânia. Ninguém sobreviveu. Imediatamente, a RTLM responsabilizou a FPR e membros da UNAMIR pelo ataque $^{26}$. Ato contínuo, iniciou-se a matança dos tutsis.

Inicialmente, os líderes do movimento de extermínio eram militares hutus com armas de fogo. Porém, logo começaram a organizar os civis hutus, com a distribuição de armas (especialmente facões), bloqueios de estradas, apelos radiofônicos, exortando-os a matarem as

\footnotetext{
${ }^{23} \mathrm{O}$ telegrama foi comunicado às principais autoridades da ONU, como Kofi Annan, Secretário-Geral, Iqbal Riza, Sub-secretário Geral, e Hedi Annabi, Diretor da Seção de África (veja-se: UNITED NATIONS. Report of the independent inquiry into the actions of the United Nations during the 1994 genocide in Rwanda, op. cit., p. 10).

${ }^{24}$ Veja-se: UNITED NATIONS. Report of the independent inquiry into the actions of the United Nations during the 1994 genocide in Rwanda, op. cit., p. 12.

${ }^{25}$ Veja-se: GOUREVITCH, Philip, 2006, op. cit., p. 107.

${ }^{26}$ O relatório da ONU informa que, depois da queda do avião, a UNAMIR recebeu várias chamadas de ministros e políticos, pedindo proteção (veja-se: UNITED NATIONS. Report of the independent inquiry into the actions of the United Nations during the 1994 genocide in Rwanda, op. cit., p. 16).
} 
"baratas" e conclamando os tutsis a se abrigarem em igrejas e outros locais supostamente seguros, exatamente onde podiam ser mais facilmente encontrados e mortos. A esse respeito, Bruce D. Jones observou:

\begin{abstract}
"a extraordinária ironia é que essa matança escalou a partir de uma guerra civil tão baixa em intensidade que ela escapou ao radar do monitoramento internacional de conflitos. (...) Aliás, o número de mortes na guerra era tão baixo que o Stockholm International Peace Research Institute categorizava a luta como 'disputa",27.
\end{abstract}

É importante notar que as tropas da ONU ofereceram pouca resistência ao massacre, enquanto governos estrangeiros fecharam embaixadas e retiraram seus cidadãos de Ruanda. Simultaneamente, o governo francês providenciou um avião militar para transferir Agathe Kanzinga para Paris. Por fim, em 9 de abril, um comitê de crise, liderado pelo Coronel Théoneste Bagasora, designou um governo interino composto exclusivamente de indivíduos leais ao Poder Hutu.

Como já dito anteriormente, o resultado seria o terceiro maior genocídio em número de mortos desde 1950. A esse respeito, os dados apresentados por Philip Gourevitch são estarrecedores: calcula-se que, em 100 dias, 800 mil pessoas foram liquidadas, o que dá uma média de 333,3 mortos por hora ou 5,5 por minuto ${ }^{28}$. Teresa Nogueira Pinto resumiu bem o que se passou:

\begin{abstract}
"A característica mais singular, e mais perturbadora, do genocídio ruandês foi ter sido um genocídio de proximidade. Entre abril e julho de 1994, o país dividiu-se de fato entre carrascos, vítimas e testemunhas. Foi um período em que professores mataram alunos, médicos mataram pacientes, padres mataram fiéis, irmãos mataram irmãos. As atividades do quotidiano ficaram suspensas e o país transformou-se num gigantesco campo de morte a céu aberto, num cenário em que a morte violenta, as pilhagens e violações se tornaram absolutamente banais, como se de uma extensão do campo de batalha se tratasse" 29 .
\end{abstract}

\title{
A inércia da comunidade internacional e a ação da França
}

Diante do morticínio, em 21 de abril, o Gal. Dallaire instou a ONU a enviar mais 5 mil homens, com carta branca para agir. Todavia, nesse mesmo dia, o Conselho de Segurança se

\footnotetext{
${ }^{27}$ JONES, Bruce D. apud ALVES, Ana Cristina Araújo. Além do Ocidente, além do Estado e muito além da Moral: por uma política eticamente responsável em relação à diferença - o caso ruandês. Contexto Internacional. Rio de Janeiro, v. 27, $\mathrm{n}^{\circ}$ 2, julho-dezembro/2005, p. 42 (disponível em: http://www.scielo.br/scielo.php?script=sci arttext\&pid=S0102-85292005000200002\&Ing=pt\&nrm=iso - acesso em 27/7/2013).

${ }^{28}$ Idem, p. 130.

${ }^{29}$ PINTO, Teresa Nogueira, 2011, op. cit., p. 48.
} 
reuniu, decidindo reduzir o contingente da UNAMIR em 90\%, isto é, a 270 homens ${ }^{30}$. Assinale-se que essa decisão pode ser considerada a maior vitória do Poder Hutu, e deve ser creditada aos EUA que, em virtude dos ataques sofridos por seus soldados na Somália, em outubro de $1993^{31}$, havia acabado de editar uma decisão presidencial cujo teor consistia em apontar razões para evitar o envolvimento norte-americano em missões de paz da ONU. Tanto que, em maio de 1994, quando o Conselho de Segurança aprovou o envio de 5.500 homens para Ruanda, os EUA conseguiram impor restrições, de tal forma que isto fosse feito muito lentamente ${ }^{32}$.

Em face da inércia internacional - inclusive da Igreja Católica -, em junho de 1994, oito países africanos anunciaram disposição de enviar a Ruanda uma força de intervenção, para o quê solicitaram aos EUA a remessa de 50 carros de transporte de tropas blindados. Ironicamente, o governo norte-americano concordou em arrendar os veículos à ONU por US\$ 15 milhões, embora a dívida do país com as Nações Unidas chegasse a bilhões de dólares. De outra parte, a França, que havia fornecido milhares de armamentos a Ruanda, adotou uma postura voltada exclusivamente para a tentativa de salvar seus investimentos, bem como o prestígio político e militar. Dessa forma, procurou tentar justificar o massacre como resultado da fúria popular, acusando a FPR de agressão. Segundo o governo francês, a matança podia ser explicada por razões tribais.

Diante da reação da imprensa francesa, que passou a responsabilizar o governo de participar da preparação e da implementação do genocídio, as autoridades da França anunciaram, em junho de 1994, o envio de uma expedição sob a bandeira da ONU, o que foi autorizado pelo Conselho de Segurança. Finalmente, em 23 de junho, as primeiras tropas da

\footnotetext{
${ }^{30}$ Veja-se: UNITED NATIONS. Report of the independent inquiry into the actions of the United Nations during the 1994 genocide in Rwanda, op. cit., p. 23.

31 A Missão de Paz da ONU na Somália (UNOSOM I) foi criada em abril de 1992, com o objetivo de enviar ajuda humanitária para as vítimas da guerra civil somali, iniciada em 1990. Em maio de 1993, a missão foi substituída pela UNOSOM II, com participação de diversos países. Entre os dias 3 e 4 de outubro do mesmo ano, num confronto entre forças dos EUA e milicianos somalis, dezoito soldados norte-americanos foram mortos, naquela que ficou conhecida como Batalha de Mogadíscio.

${ }^{32}$ Veja-se: UNITED NATIONS. Report of the independent inquiry into the actions of the United Nations during the 1994 genocide in Rwanda, op. cit., p. 26.
} 
Opération Turquoise deslocaram-se para o nordeste de Ruanda ${ }^{33}$, sob protestos de Nelson Mandela, presidente da África do Sul, e do Bispo Desmond Tutu.

Imediatamente, os porta-vozes das tropas francesas começaram a divulgar a idéia de um duplo genocídio, tendo em vista que o exército da FPR provocava o recuo das forças ruandesas. A partir de então, a estratégia do Poder Hutu passou a ser a condução de multidões para o exílio, com o objetivo de estabelecer um Estado de refugiados nos campos da ONU, no que seria auxiliado pelas forças francesas.

De fato, a França procurou transformar a ação supostamente humanitária em "área protegida”, sustentando e dando guarida às lideranças políticas do genocídio. Ao que tudo indica, o objetivo principal da Opération Turquoise era garantir que a matança continuasse por mais um mês para assegurar ao comando genocida uma transferência segura para o Zaire. Finalmente, no início de julho de 1994, o massacre foi estancado, quando a FPR conseguiu entrar em Butare e Kigali, embora começasse um novo morticínio: calcula-se que, em poucos dias, entre 25 mil e 60 mil hutus foram mortos por homens da FPR, em represália ${ }^{34}$. E, no dia 12 de julho, o Comitê Internacional da Cruz Vermelha anunciava que cerca de 1 milhão de pessoas haviam morrido.

Com a vitória da FPR, estima-se que 500 mil hutus atravessaram a fronteira para Goma, no Zaire, entre os dias 14 e 15 de julho. E no dia 16, o chefe do Poder Hutu fugiu para a Zone Turquoise. Por fim, em 19 de julho de 1994, tomava posse o novo governo, formado por uma coalizão da FPR com membros dos partidos de oposição ao Poder Hutu.

\section{A continuidade da guerra fora das fronteiras de Ruanda e a tentativa de reorganização do Estado ruandês}

Em face dos milhares de refugiados, as condições sanitárias dos acampamentos logo entraram em colapso, tanto que os primeiros casos de cólera foram relatados ainda no dia 20 de julho de 1994. Por outro lado, esses mesmos acampamentos foram organizados como réplicas do Estado montado pelo Poder Hutu. Aliás, ex-membros das Forças Armadas de Ruanda (FAR) e da Interahamwe imediatamente procuraram se estabelecer em todo e qualquer lugar onde houvesse um acampamento da ONU, e os refugiados que tentassem voltar a Ruanda eram acusados de cumplicidade com a FPR e mortos por milícias

${ }^{33}$ Veja-se: UNITED NATIONS. Report of the independent inquiry into the actions of the United Nations during the 1994 genocide in Rwanda, op. cit., pp.29-31.

${ }^{34}$ Veja-se: DIAMOND, Jared, 2005, op. cit., p. 383. 
organizadas. Ao mesmo tempo, os chamados génocidaires empreendiam freqüentes incursões nas áreas próximas dos campos, aterrorizando as comunidades vizinhas por meio de ataques a tutsis sobreviventes e a hutus que pudessem testemunhar contra eles. Dessa forma, os acampamentos de fronteira acabaram por transformar o problema de Ruanda numa crise regional.

Restava, contudo, a questão da reconstrução do Estado. Um primeiro problema referese à própria miséria: estimativas do BIRD apontam para o fato de que, logo depois do genocídio, Ruanda se tornou o país mais pobre do mundo, com renda per capita de US\$ 80. Assim, muitas vezes, os acampamentos da ONU significavam condições de vida melhores do que na terra natal. As carências eram tão grandes que muitos bens doados por organizações humanitárias se tornaram objeto de comércio.

O novo governo procurou adotar um discurso de reconciliação e de unidade nacional, inclusive com a abolição das cédulas de identidade étnica. Porém, a reconciliação se mostrava praticamente impossível, tendo em vista que a FPR exigia que o genocídio fosse reconhecido como o evento definidor na História de Ruanda, enquanto o Poder Hutu procurava transformar a matança em algo indistinguível da própria evolução ruandesa. Ademais, todos sabiam quem eram seus vizinhos. A depressão se tornou epidêmica entre a população, e os sobreviventes procuravam uns aos outros, buscando formar famílias substitutas, que se aglomeravam em barracões. A orfandade constituía um fenômeno gravíssimo: calcula-se que, dois anos após o genocídio, cerca de 100 mil crianças cuidavam umas das outras ${ }^{35}$.

Por outro lado, havia a questão da movimentação populacional, pois logo no início de 1995, aproximadamente 750 mil exilados tutsis e quase 1 milhão de cabeças de gado retornaram a Ruanda, substituindo os mortos na razão de 1:1. É preciso assinalar que grande parte dessas pessoas havia nascido no exílio, sendo atraídas pelas habitações vazias dos mortos e pela possibilidade de obter lucros com a venda de qualquer coisa. Assim, em 1996, mais de $70 \%$ das pessoas que viviam em Kigali e Butare eram recém-chegadas a Ruanda ${ }^{36}$.

Existia, de outra parte, a questão da punição dos responsáveis pela matança. Ainda em abril de 1995, mais de 33 mil pessoas, incluindo homens, mulheres e crianças, haviam sido presas por supostamente ter participado do morticínio. Esse número saltaria para $60 \mathrm{mil} \mathrm{em}$

\footnotetext{
${ }^{35}$ Veja-se: GOUREVITCH, Philip, 2006, op. cit., p. 222.

${ }^{36}$ Idem, pp. $224-226$.
} 
fins de 1995. E, no final de 1997, havia pelo menos 125 mil hutus detidos, sob acusação de crimes diversos durante o genocídio ${ }^{37}$.

Diante desses números, havia, evidentemente, obstáculos de ordem prática: como conduzir dezenas de milhares de processos judiciais por homicídio? Há que considerar ainda que a legislação do país admite a pena de morte, e as condenações fatalmente implicariam nova matança. Por outro lado, a lista de procurados em Ruanda constituía um verdadeiro saco de gatos, sendo impossível estabelecer sequer uma hierarquia de acordo com a gravidade das acusações. Finalmente, os investigadores acabaram por elaborar um rol com aproximadamente 400 nomes daqueles que teriam tido posição de comando no genocídio, e a ONU organizou o Tribunal Penal Internacional para Ruanda, que se estabeleceu em Arusha, na Tanzânia. Todavia, a corte jamais mostrou empenho em apurar realmente as responsabilidades.

Mas a guerra não havia terminado, pois entre 1995 e 1996, as forças do Poder Hutu no exílio continuavam a guerrilha, incorporando e treinando grande número de zairenses de ascendência ruandesa para a retomada da luta étnica, sem que houvesse qualquer repressão por parte do governo do Zaire.

A esse respeito, é preciso considerar o papel de Mobutu Sese Seko e dos países do Ocidente. Com efeito, embora liderasse uma feroz ditadura no Zaire, Mobutu jamais havia sido incomodado, tendo em vista os interesses das potências ocidentais durante a guerra fria. Porém, com o desaparecimento do socialismo real, no início da década de 1990, Mobutu perdeu qualquer utilidade para o Ocidente, que retirou a ajuda. Dessa forma, agravou-se a crise econômica e a hiperinflação atingiu o país, provocando, em fins de 1993, um motim do exército zairense.

Em face do genocídio em Ruanda, porém, lideranças ocidentais voltariam a cortejar Mobutu, que passou a ser visto como intermediário na solução de conflitos regionais. A França chegou mesmo a restaurar a ajuda ao Zaire. De seu lado, Mobutu passou a manipular a questão étnica com vistas a recompor seu poder: o resultado foram ataques e saques promovidos pelo Poder Hutu e por forças do governo zairense aos banyamulenges (os cerca de 400 mil tutsis que viviam no Zaire), em setembro de 1996.

Todavia, os banyamulenges resistiam e, em outubro de 1996, foram intimados a deixar o país em uma semana. Em resposta, o novo governo de Ruanda aliou-se às forças guerrilheiras de Laurent Kabila, atacando as tropas de Mobutu. Assim, logo nas primeiras

\footnotetext{
${ }^{37}$ Idem, p. 236.
} 
semanas de combate no Zaire, milhares de refugiados dos campos voltaram para Ruanda, iniciando-se uma repatriação em massa. Em seguida, a Tanzânia determinou o fechamento dos acampamentos em seu território, ordenando também o repatriamento dos ruandeses. Para se ter uma idéia do movimento populacional que isto representou, estima-se que o número de retornados chegou a 1,5 milhão em apenas seis meses. Finalmente, em 17 de maio de 1997, Kabila anunciava vitória, declarando-se presidente do Zaire e mudando o nome do país para República Democrática do Congo. Mas, como se sabe, a guerra regional não estaria terminada.

\section{Por que ocorreu o genocídio?}

O genocídio ocorrido em Ruanda, entre abril e julho de 1994, levou os estudiosos a levantar algumas hipóteses para tentar explicá-lo. Para alguns, o morticínio teria resultado de um surto de fúria coletiva, enquanto outros procuram analisá-lo como reflexo de ódios de classe, em virtude da secular opressão dos tutsis sobre os hutus. Há também aqueles que vêem a mortandade como conseqüência de manipulação ideológica das massas por uma oligarquia cujo objetivo era manter o controle do Estado. Finalmente, há os que identificam em Ruanda uma situação de superpovoamento em relação aos recursos disponíveis, apresentando uma visão malthusiana dos conflitos que levaram à matança.

Porém, como bem apontou Philip Gourevitch, a carnificina suscita algumas questões importantes: se o genocídio resultou de loucura coletiva, de uma explosão de hordas, ou de um ódio coletivo que se transformou em crime passional de massa, o que teria levado os hutus, durante a matança, a suportar a exaustão, a confusão e a sujeira?

O próprio Gourevitch indica algumas respostas. Para ele, uma violência coletiva de tal magnitude necessita ser organizada, e a destruição requer um grande objetivo, o desejo de alcançar uma nova ordem, que precisa ser, ao mesmo tempo, concebida como algo simples e absoluto. Tanto que a população de Ruanda denomina a velha ordem de "antes". Ou seja: haveria uma ideologia do genocídio, pela qual o desejo de que a vítima morresse se tornou uma necessidade. Em Ruanda, essa ideologia tomou o nome de Poder Hutu, cujo grito de estímulo era: "faça o seu trabalho" ${ }^{\text {"38 }}$. Os hutus que se opunham a essa ideologia acabaram por ser acusados de cumplicidade com os tutsis e foram os primeiros a serem mortos.

\footnotetext{
${ }^{38}$ Idem, p. 17.
} 
Mas isso não explicaria por que as pessoas obedeceram. A resposta de Gourevitch está fundamentada na própria tradição cultural ruandesa, baseada num extremo respeito à autoridade e na reverência ao poder. Assim, pessoas influentes e homens de negócios teriam manipulado essa tendência à submissão, tornando-se as grandes figuras do genocídio ${ }^{39}$. Por outro lado, é preciso considerar a baixíssima escolaridade da população: de fato, no início da década de 1960, na ocasião da independência, não existia, em Ruanda, nenhuma pessoa com curso superior. Dessa forma, haveria, por parte das massas, grande receptividade a discursos voltados para a construção de uma nova ordem.

No que diz respeito à hipótese de um ódio secular de classes, é preciso considerar que, realmente, pelo menos desde meados do século XIX, os tutsis constituíam uma casta privilegiada de criadores de gado. Essa condição foi acentuada pelo poder colonial, gerando um ressentimento e um ódio que explodiram, primeiramente, no início da década de 1960, depois em 1973 e, finalmente, em 1994. Porém, Jared Diamond levanta algumas perguntas que contestam essa explicação: por que os pigmeus, que nunca passaram de $1 \%$ da população, e sempre se localizaram no fundo da escala social, também foram massacrados? Por que teria ocorrido matança também numa comunidade no nordeste de Ruanda, em que havia apenas um tutsi, mas onde $5 \%$ da população foram exterminados? Por que, durante o genocídio, e à medida que diminuía o número de tutsis a serem mortos, os hutus passaram a se eliminar uns aos outros? $?^{40}$

Para Diamond, a explicação deve ser buscada na estrutura fundiária de Ruanda e na superpopulação. Considerando a alta densidade demográfica de Ruanda desde o século XIX, ele mostra que, depois da independência, o crescimento populacional teria se acomodado em função da derrubada de florestas e da drenagem de pântanos, com o objetivo de ampliar a área cultivável, e também em virtude da morte e da fuga de tutsis, ocorrida em 1973, o que aumentou a disponibilidade de terras. Assim, entre 1966 e 1981, houve um grande aumento da produção de alimentos per capita.

Contudo, essa situação começou a mudar no início da década de 1980, pois a derrubada de florestas provocou ressecamento de rios e alteração do regime de chuvas, que se tornaram mais irregulares. Em consequiência, a fome reapareceu em fins dos anos 80. O

\footnotetext{
${ }^{39}$ Idem, pp. 23-24.

${ }^{40}$ Veja-se: DIAMOND, Jared, 2005, op. cit., pp. 384-386.
} 
problema teria sido agravado pela estrutura fundiária, que levou a uma extrema fragmentação do solo.

Diamond exemplifica a questão com o caso da comuna de Kamana que, embora possuísse solo fértil, era densamente povoada mesmo para os padrões de Ruanda: em 1988, a população era de 572 habitantes $/ \mathrm{km}^{2}$, aumentando essa relação para 788 pessoas $/ \mathrm{km}^{2}$ em 1993. Por outro lado, o tamanho médio das fazendas era de 0,36 ha em 1988 , caindo para 0,29 ha em 1993, sendo que cada propriedade era subdividida em aproximadamente dez lotes. Com isso, a terra cultivável da comuna estava totalmente ocupada, e os jovens encontravam extrema dificuldade para casar e constituir famílias. Para se ter uma idéia do problema, na faixa entre 20 e 25 anos, a porcentagem de mulheres que viviam com os pais cresceu de $39 \%$ para $67 \%$, entre 1988 e 1993, e a de homens aumentou de $71 \%$ para quase $100 \%$, no mesmo período, gerando gravíssimas tensões familiares.

Outra conseqüência negativa da extrema fragmentação da terra refere-se ao déficit calórico enfrentado pela população de Kamana. De fato, Diamond mostra que, entre 1988 e 1993, o número médio de pessoas por fazenda cresceu de 4,9 para 5,3, o que, em face da baixa produtividade, significava uma deficiência de calorias da ordem de $23 \%$ /dia, e o número de habitantes com consumo inferior a 1.600 calorias/dia aumentou de $9 \%$ para $40 \%$, entre 1982 e 1990. Assim, o restante dos alimentos necessários tinha que ser comprado com a renda obtida em empregos fora da fazenda, sendo que $1 / 3$ das famílias da comuna não possuíam esse tipo de renda.

Diamond alerta ainda para o fato de que esses números escondem enormes desigualdades, pois os lotes grandes aumentaram de 5\% para 8\%, entre 1988 e 1993, enquanto a quantidade de lotes minúsculos cresceu de $36 \%$ para $45 \%$, no mesmo período. A este fato acrescente-se a questão de que a renda obtida fora da fazenda era maior entre aqueles que possuíam mais terra, permitindo que os mais abastados comprassem as áreas dos mais pobres, ampliando-se as diferenças sociais. Para o autor, as disputas por terras acabaram por minar o tecido social de Ruanda, pois as contendas passaram a ser dirimidas nos tribunais, tornando o conflito crônico ${ }^{41}$.

Essa visão é, em certa medida, corroborada por Alison des Forges, para quem a disponibilidade de terra em Ruanda é insuficiente para alimentar a população, o que é agravado pela erosão do solo e por padrões de posse extremamente complexos, derivados de

\footnotetext{
${ }^{41}$ Idem, pp. 388-392.
} 
fatores históricos e de movimentos populacionais. É importante assinalar que o texto de des Forges é de 2006, e nele a autora alerta para a situação potencialmente violenta da estrutura fundiária mais de dez anos após o genocídio ${ }^{42}$.

De fato, ela lembra que, até 2005, a posse era regulada por três sistemas diferentes, sendo dois deles costumeiros e um escrito, este último introduzido pela administração colonial. Essa situação foi agravada quando da vitória da FPR, pois mais de 600 mil exilados, muitos deles tutsis criadores de gado, retornaram ao país com seus rebanhos, passando a ocupar suas antigas terras ou as áreas abandonadas pelos hutus. Ademais, em 1996, dezenas de milhares de pessoas de uma nova geração de refugiados voltaram a Ruanda, e muitos encontraram suas terras já ocupadas pelos retornados em 1994/1995. Assim, no final do século XX, o problema fundiário continuava extremamente conflituoso, e a FPR, controlada por soldados e intelectuais que não conhecem a questão, se mostrou incapaz de dar uma solução.

Na verdade, a FPR atribui à agricultura um grande potencial para o desenvolvimento do país, mas considera que a baixa produtividade decorre do pequeno tamanho dos lotes e de métodos arcaicos de cultivo. Assim, desde o início, procurou impor uma mudança radical na estrutura fundiária, aprovando, em 2005, uma lei de terras pela qual a produção agrícola deve ser moderna e profissional, voltada para a exportação. A nova legislação provocou a imediata expulsão dos pequenos agricultores de suas terras, os quais deveriam, supostamente, encontrar trabalho nas propriedades modernas ou nas cidades. Alguns seriam recompensados por um programa de aldeamento, mas isso não ocorreu, pois a maior parte das terras acabou nas mãos de militares ou de pessoas ricas, muitos dos quais viviam em Kigali ${ }^{43}$.

Essa interpretação é contestada pelo relatório da organização Human Rights Watch, intitulado Leave none to tell the story: genocide in Rwanda. Segundo o relatório,

“este genocídio não foi uma explosão incontrolável de ódio por um povo consumido
por 'antigo ódio tribal' (...) este genocídio resulta da escolha deliberada da elite
moderna para espalhar ódio e medo para se manter no poder. Este grupo pequeno e
privilegiado primeiro lançou a maioria contra a minoria para fazer frente à crescente
oposição política em Ruanda. Então, confrontados com o sucesso da FPR no campo
de batalha e na mesa de negociação, esses poucos detentores do poder
transformaram a estratégia de divisão étnica em genocídio. Acreditavam que a

\footnotetext{
${ }^{42}$ Veja-se: DES FORGES, Alison. Land in Rwanda: winnowing out the chaff. L'Afrique des Grands Lacs. Annuaire 2005-2006, p. 353 (disponível em: http://www.ua.ac.be/objs/00151020.pdf - acesso em 27/5/2010).

${ }^{43}$ Idem, pp. 359-362.
} 
campanha de extermínio restauraria a solidariedade dos hutus sob sua liderança e os ajudaria a ganhar a guerra",44.

Em certa medida, essa visão é corroborada pelo Gal. Dallaire, comandante das tropas da UNAMIR que, em entrevista concedida em 2003, declarou:

\begin{abstract}
"havia uma operação sendo planejada. Se esta operação era claramente um genocídio, ou se, na verdade, estavam sendo articulados limites, penso que o objetivo era eliminar os moderados. Disso não há dúvidas. O extermínio dos demais e a continuação da matança podem ter sido apenas um evento fortuito, mas havia uma estrutura estabelecida, de tal forma que é possível que tenha sido deliberado".
\end{abstract}

E acrescentou mais um dado: "A pergunta que me faço (...) é: por que levou tanto tempo para a Frente Patriótica de Ruanda (FPR) deter o genocídio? Por que demorou 3 meses e meio?" 45 .

Quaisquer que sejam os motivos, há uma questão apontada por Philip Gourevitch que deve ser considerada: o que teria levado os hutus, durante o genocídio, a suportar o caos e a imundície provocados por eles mesmos?

O próprio Gourevitch indica um aspecto extremamente importante do processo de mobilização para o morticínio. Segundo ele, os hutus teriam recebido um grande incentivo para participar da matança, que foi o loteamento antecipado dos pertences dos tutsis. Por outro lado, de acordo com os líderes da campanha para o desencadeamento do massacre, o trabalho de matar não era visto como crime, mas sim como a lei local, tornando-se cada cidadão responsável pela sua aplicação. Para Gourevitch, os autores do genocídio perceberam que, para levar um grande número de pessoas a fazer o mal, é necessário apelar para o seu desejo de potência. Ou seja: a força que move as pessoas é o poder, e a orgia de poder em Ruanda foi perpetrada em nome do hutuísmo ${ }^{46}$.

\title{
Por que a comunidade internacional não tentou impedir o genocídio?
}

Analisados os motivos que teriam levado ao desencadeamento do genocídio em Ruanda, restam algumas questões, extremamente importantes: por que a comunidade

\footnotetext{
${ }^{44}$ Apud DIAMOND, Jared, 2005, op. cit., p. 384.

45 Conforme: DALLAIRE, Roméo Alain, Gal. Frontline: ghosts of Rwanda, p. 4 (disponível em: http://www.pbs.org/wgbh/pages/frontline/shows/ghosts/interviews/dallaire.html - acesso em 18/9/2010) (tradução nossa: MGM).
}

${ }^{46}$ Veja-se: GOUREVITCH, Philip, 2006, op. cit., pp. 121-126. 
internacional nada fez para impedir a matança? Por que, uma vez iniciado o morticínio, não houve intervenção de outros países? Por que a ONU, em lugar de aumentar seu contingente no país, reduziu-o drasticamente, mesmo depois das advertências do Gal. Dallaire? Por que a Convenção do Genocídio, de 1948, que conclama os demais países a fazerem alguma coisa para tentar impedir uma carnificina como essa, não foi considerada?

A propósito dessas questões, é preciso levar em conta um primeiro aspecto, apontado no próprio relatório das Nações Unidas sobre o genocídio: a análise da situação política em Ruanda, elaborada tanto pela UNAMIR como pelos demais órgãos da ONU, teria sido deficiente. Segundo o relatório, na sede da instituição

"não se prestou a devida atenção e não se destinaram recursos institucionais para um
alerta precoce e para uma análise dos riscos. Poder-se-ia ter avançado muito com
uma política preventiva mais ativa, encarregada de identificar os riscos de conflito
ou tensão, incluindo-se uma cooperação institucional com os meios acadêmicos,
organizações não governamentais e uma melhor coordenação entre as diferentes
partes do sistema das Nações Unidas encarregadas de Ruanda"

Porém, cabe perguntar: o que teria levado a ONU a cometer tais falhas? O interessante é que o mesmo relatório oferece uma resposta bastante plausível, ao mencionar a falta de interesse estratégico de Ruanda para importantes países-membros da entidade ${ }^{48}$.

Outro aspecto, apontado por Michael Barnett, refere-se ao fato de que a tragédia ruandesa difere de outras ocorridas na época (como na Guerra da Bósnia, entre 1992 e 1995), principalmente porque poderia ter havido intervenção a baixo custo. Para Barnett, além da total indiferença com uma carnificina que se passava nos confins da África, a não intervenção se explica também por questões relativas à burocratização do chamado dever de ajuda. Aliás, essa burocratização pode ser vista na própria interpretação dada pela ONU ao dever de ajuda, isto é, no modo como seus líderes se valeram das regras de manutenção da paz para concluir que, nas primeiras semanas do genocídio, não havia, de fato, dever de ajuda, já que a matança seria resultante de uma guerra civil.

De acordo com Barnett, há muito tempo a atitude dos membros da ONU é moldada segundo regras sociais e burocráticas que definem o que é ou não apropriado e ético. Muitas vezes, o que se tem como antiético, os burocratas instalados em Nova York consideram ético. Isto se explica pelo fato de que o Conselho de Segurança, originalmente criado como um foro para a manutenção da paz e da segurança internacionais, foi levado, em função da guerra fria,

\footnotetext{
${ }^{47}$ UNITED NATIONS. Report of the independent inquiry into the actions of the United Nations during the 1994 genocide in Rwanda, op. cit., p. 44 (tradução nossa - MGM).

${ }^{48}$ Idem, p. 46.
} 
a uma preocupação exclusiva com a segurança. Assim, as supostas neutralidade e imparcialidade tornaram-se as regras básicas do organismo, e a ONU passou a trabalhar com estreitas noções de soberania e de honra ao princípio da não-intervenção.

Todavia, e mesmo com o fim da guerra fria - que levou à redefinição do que é ou não ameaça à paz e à segurança -, o Conselho continuou a se ocupar primordialmente desta última, reduzindo drasticamente os casos de necessidade de manutenção da paz. Ademais, é preciso considerar também que, depois do fim do socialismo real, as tragédias humanitárias se tornaram muito mais freqüentes, e a ONU não tem condições políticas, logísticas ou financeiras de participar de todos os casos que requerem auxílio.

Isto levou seus burocratas ao desenvolvimento de regras baseadas em considerações éticas, com o objetivo de evitar que o dever de ajuda sufoque a instituição. O problema foi agravado a partir de outubro de 1993, quando os eventos da Somália expuseram claramente os riscos a que estavam sujeitas as forças de paz. Dessa forma, os funcionários da ONU passaram a tomar enorme cuidado, não para proteger os soldados envolvidos em missões de paz, mas para cuidar melhor dos interesses da própria organização. Essa decisão foi consubstanciada na resolução do Conselho de Segurança, aprovada em 3 de maio de 1994, e que dispunha sobre autorização para operações de paz.

E é essa visão que teria orientado os burocratas da ONU que, em vez de intervir, reduziram os contingentes já instalados em Ruanda quando se iniciou o genocídio. Ou seja: o Secretariado Geral concluiu que, no caso ruandês, não havia dever de ajuda e, se havia algum dever, era o de garantir a sobrevivência da própria instituição ${ }^{49}$.

De qualquer modo, cabe ressaltar que, como está reconhecido no próprio relatório das Nações Unidas, "este fracasso deixou feridas profundas na sociedade ruandesa e nas relações entre Ruanda e a comunidade internacional, especialmente a $O N U^{, 50}$. E o relatório complementa:

"O fracasso da ONU em prevenir e, posteriormente, deter o genocídio em Ruanda foi um fracasso do sistema das Nações Unidas em seu conjunto. O fracasso fundamental foi a falta de recursos e de compromisso político dedicado aos acontecimentos de Ruanda e à presença das Nações Unidas no país. Houve uma falta

\footnotetext{
${ }^{49}$ Veja-se: BARNETT, Michael. Bureaucratizing the duty to aid: the United Nations and Rwandan genocide, pp. 175-186 (disponível em: http://www.newschool.edu/uploadedFilles/TCDS/Democracy_and_Diversity_Institutes/Barnett_Bureaucratizing \%20the\%20Duty\%20to\%20Aid.pdf - acesso em 27/5/2010).

${ }^{50}$ UNITED NATIONS. Report of the independent inquiry into the actions of the United Nations during the 1994 genocide in Rwanda, op. cit., p. 3 (tradução nossa - MGM).
} 
reiterada de vontade política da parte dos Estados-membros para atuar (...). Finalmente, e apesar de a UNAMIR ter padecido de uma carência crônica de recursos e prioridade política, é preciso dizer que foram praticados erros graves com Considerações finais os recursos à disposição da ONU" ${ }^{, 51}$.

Depois do genocídio, os problemas de Ruanda eram desesperadores: um país paupérrimo, sem grandes riquezas naturais, super-povoado (apesar do morticínio), com milhares de órfãos, mutilados e retornados sem qualquer perspectiva, e uma economia baseada quase que exclusivamente na agricultura, cuja estrutura só acentuava as dificuldades, uma vez que o parcelamento excessivo da terra impedia a adoção de quaisquer medidas para o aumento da produtividade.

Diante disso, o novo governo ruandês procurou estabelecer políticas com vistas a promover minimamente o desenvolvimento do país e superar os problemas econômicos e sociais que haviam contribuído para gerar a crise que conduziu ao genocídio. Nesse sentido, adotou um programa intitulado "Visão 2020", cuja principal estratégia era a eliminação da pobreza e a transformação de Ruanda numa nação de renda média. Para tanto, o documento estabelecia o objetivo de aumentar a renda per capita de US\$290 para US\$900, no período compreendido entre 2000 e 2020, ao mesmo tempo em que estimava o crescimento da população de 8 milhões para 16 milhões. Todavia, os dados disponíveis apontam uma dificuldade muito grande em atingir as metas, tendo em vista que, em 2007, a renda bruta por domicílio havia se elevado para apenas US\$ 371, enquanto a população havia aumentado para 9 milhões de habitantes. E, apesar do crescimento da renda, a desigualdade social se ampliou pois, se em 2001, o índice de GINI era de 0,47, em 2006, passou para 0,51 52 .

Estas dificuldades estão ligadas, acima de tudo, à própria pobreza de Ruanda e às características de sua economia. De fato, o orçamento para o ano de 2009/2010 totalizava US\$ 1,5 bilhão, e os principais setores a serem contemplados eram: educação (US\$ 249,5 milhões), transportes (US\$ 186,1 milhões), saúde (US\$ 153,8 milhões) e agricultura (US\$ 99,8 milhões), restando, portanto, para todos os demais setores, apenas US\$ 700 milhões.

\footnotetext{
${ }^{51}$ Idem, pp. 3-4.

${ }^{52}$ Veja-se: GRIMM, Sven et al. Coordinating China and DAC development partners: challenges to the aid architecture in Rwanda. Bonn: Deutsches Institut für Entwicklugspolitik, 2010, p. 29.
} 
Dessa forma, verifica-se que Ruanda é gravemente dependente de ajuda externa, uma vez que a arrecadação só consegue contemplar $50 \%$ dos gastos ${ }^{53}$.

Uma última questão, para a qual ainda não há resposta, refere-se às perspectivas reais de reconstrução do país. Nesse caso, e independentemente da ajuda estrangeira, é impossível qualquer prognóstico, não somente pelas condições econômicas extremamente precárias da região, mas porque ninguém sabe como se recompõe um tecido social totalmente estraçalhado, no qual grande parte da população é composta de assassinos. De qualquer modo, em 1994, o mundo assistiu passivamente à dilaceração de Ruanda, e agora ninguém está preocupado com as dificuldades de reconstrução de um lugar sem significado estratégico e que não dispõe de grandes riquezas naturais.

\section{Referências Bibliográficas:}

ALVES, Ana Cristina Araújo. Além do Ocidente, além do Estado e muito além da Moral: por uma política eticamente responsável em relação à diferença - o caso ruandês. Contexto Internacional. Rio de Janeiro, v. 27, $\mathrm{n}^{\mathrm{o}}$ 2, julho-dezembro/2005 (disponível em: http://www.scielo.br/scielo.php?script=sci_arttext\&pid=S0102-

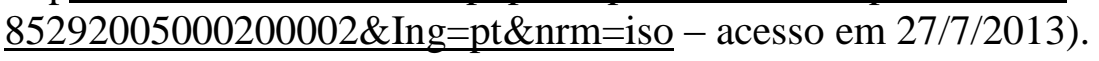

BARNETT, Michael. Bureaucratizing the duty to aid: the United Nations and Rwandan genocide (disponível em: http://www.newschool.edu/uploadedFiles/TCDS/Democracy_and_Diversity_Institutes/Barnet t Bureaucratizing\%20the\%20Duty\%20to\%20Aid.pdf - acesso em 27/5/2010).

COQUERY-VIDROVITCH, C.; MONIOT, H. África negra: de 1800 a nuestros días . Barcelona: Labor, 1976.

DALLAIRE, Roméo Alain, Gal. Frontline: ghosts of Rwanda (disponível em: http://www.pbs.org/wgbh/pages/frontline/shows/ghosts/interviews/dallaire.html - acesso em $\underline{18 / 9 / 2010}$.

DES FORGES, Alison. Land in Rwanda: winnowing out the chaff. L'Afrique des Grands Lacs. Annuaire 2005-2006 (disponível em: http://www.ua.ac.be/objs/00151020.pdf - acesso em 27/5/2010).

DIAMOND, Jared. Malthus na África: o genocídio em Ruanda In: Colapso. Rio de Janeiro: Record, 2005.

GOUREVITCH, Philip. Gostaríamos de informá-lo de que amanhã seremos mortos com nossas famílias. São Paulo: Companhia das Letras, 2006.

GRIMM, Sven et al. Coordinating China and DAC development partners: challenges to the aid architecture in Rwanda. Bonn: Deutsches Institut für Entwicklugnspolitik, 2010.

${ }^{53}$ Idem, p. 33.

BJIR, Marília, v.2, n.2, p.300-328 Maio/Ago. 2013 
KAPUSCINSKI, Ryszard. Uma palestra sobre Ruanda In: Ébano. São Paulo: Companhia das Letras, 2002.

KI-ZERBO, Joseph. História da África negra. Lisboa: Publicações Europa-América, s.d., 2 v.

MAQUET, J. J. El reino de Ruanda In: FORDE, Daryll, org. Mundos africanos. México: Fondo de Cultura Económica, 1975.

OGOT, B. A. A região dos grandes lagos In: NIANE, D. T., org. História geral da África: a África dos século XII ao século XVI. São Paulo: Ática/UNESCO, 1988, v. 4.

PINTO, Teresa Nogueira. Ruanda: entre a segurança e a liberdade. Relações Internacionais. Lisboa, $\quad \mathrm{n}^{\mathrm{O}} \quad 32, \quad$ dezembro/2011 (disponível em: http://www.scielo.gpeari.mctes.pt/acielo.php?cript=sci_arttext\&pid=S1645-

91992011000400004\&Ing=pt\&nrm=iso - acesso em 27/7/2013).

SPEKE, John Hanning. The journal of the discovery of the source of the Nile. Nova York: Harper \& Brothers, 1864 (disponível em: http://books.google.com.br/books?id=W1YMAAA).

TAYLOR, Christopher C. Sacrifício rei, Estado ruandês e genocídio. Caderno CRH. Salvador, v. 24, $\mathrm{n}^{\mathrm{o}}$ 61, janeiro-abril/2011 (disponível em: http://www.scielo.br/scielo.php?script=sci_arttext\&pid=S010349792011000100005\&Ing=pt\&nrm=iso - acesso em 27/7/2013).

UNITED NATIONS. Report of the independent inquiry into the actions of the United Nations during the 1994 genocide in Rwanda (disponível em: www.un.or/news/dh/latest/rwanda.htm - daccess-dds-ny.un.org.doc/UNDOC/GEN/N99/395/50/IMG/N9939550.pdf?OpenElement acesso em 27/7/2013).

VANSINA, Jan. Antecedents to modern Rwanda. Madison, Wisconsin: The University of Wisconsin Press, 2004.

Recebido em: Junho 2013

Aprovado em: Agosto 2013 